\title{
sciendo
}

CIVIL AND ENVIRONMENTAL ENGINEERING REPORTS

E-ISSN 2450-8594

CEER 2020; 30 (4): 0072-0089

DOI: $10.2478 /$ ceer-2020-0051

Original Research Article

\section{THE MAIN FEATURES OF HYDRAULIC FILL SOILS AND RIVER DNIEPER ALLUVIAL DEPOSITS IN THE KYIV REGION}

\author{
Andriy RASHCHENKO, Tatyana DYPTAN, Oleg MALYSHEV ${ }^{1}$ \\ Kyiv National University of Construction and Architecture
}

\begin{abstract}
The features of the tectonic structure together with the geological and geomorphological zoning of Kyiv city are highlighted in the article. Particular attention is paid to the floodplains of the Dnieper River, which were formed by the hydraulic fill method. As a rule, such sites were created for new constructions and were quickly built up with low rise buildings, the bases of which were made using such hydraulic soils. Completed engineering-geological investigations of sites after hydraulic filling and observation of the base deformation over time allowed setting of the basic regularity and rules for construction on such territories. The ongoing development of the city has also covered these territories, where high-rise buildings, shopping malls, and other buildings are actively being built, and the loads from these must be transferred to reliable bases.
\end{abstract}

Keywords: alluvial deposits, floodplain, hydraulic fill of sandy soils, hydraulic fill soils, consolidation, deformations, construction methods

\section{INTRODUCTION}

One of the directions of Kyiv's territorial development is to find ways of utilizing land generally unsuited to construction. Historically, many cities have been located on the banks of rivers and in their floodplains. During flooding, large areas of these territories become submerged. The development of such territories

\footnotetext{
${ }^{1}$ Corresponding author: Kyiv National University of Construction and Architecture, e-mail: omalyshev@ukr.net
} 
involves the creation of sites near the river which will be raised to non-floating marks by the hydraulic fill method. Artificial hydraulic preparation of sands significantly differs from natural laying of sand due to the specific nature of its packing, both in the physical characteristics and in the deformations which develop over time.

Analysis of the most recent research shows that they are characterized by general patterns being self-consolidations, consolidations, and stabilization.

The investigation site for this study, which was used for research within the international Pile-test program, is located on a hydraulic fill territory administratively located in the northern part of Kyiv city and is indicated by Redchinskaya and Bogatyrskaya streets.

The main aim of the study is to investigate the features of the River Dnieper floodplain soil formation within the limits of Kyiv city through analysis of the basic methods of soil hydraulic fill used in Kyiv, based on archive experimental data analysis of the basic characteristics of hydraulic fill soils within the Dipro river floodplain, and show possible foundation deformations of buildings which were built on these territories

\section{REGIONAL ENGINEERING GEOLOGICAL CHARACTERISTICS OF THE RIVER DNIEPER VALLEY}

The territory of Ukraine refers to the Eastern European platforms, which consist of the following main tectonic structures (fig.1) [7, 8]: 1 - Ukrainian Crystalline Massif; 2 - Kovel's speech; 3 - Volyno-Podilsky plate; 4 - Carpathian fold region; 5 - Western European platform; 6 - Dnepr-Donetsk depression; 7 - Voronezh massif; 8 - Donetsk fold region; 9 - Black Sea Basin; 10 - Scythian plate; 11 - Crimean folding system.
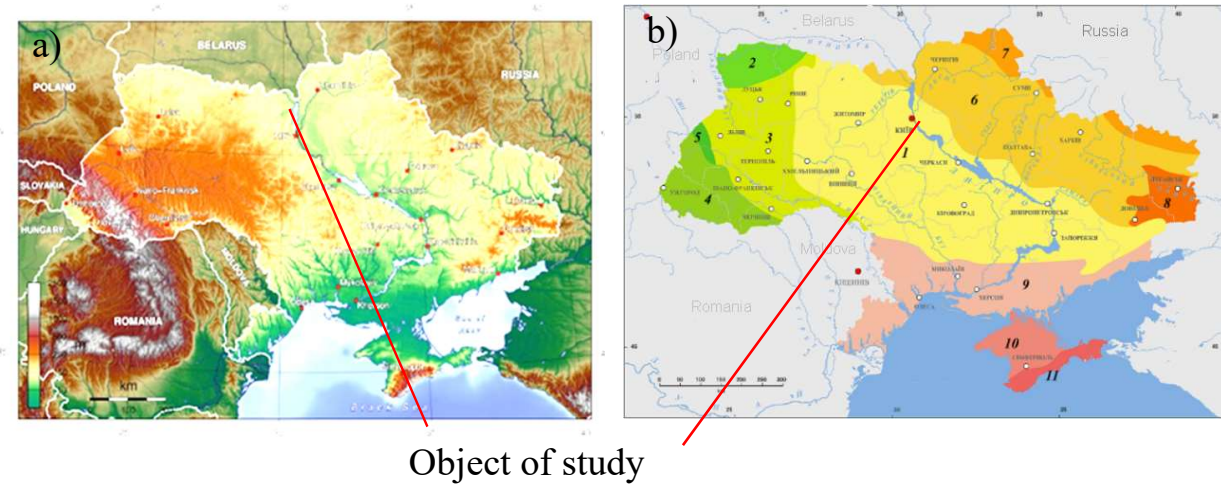

Object of study

Fig.1. The main tectonic structures of the territory of Ukraine [7, 8]:

a) tectonic map; b) relief map 


\subsection{Tectonic characteristics of the study area}

A large part of the territory of Ukraine rests on the Ukrainian Crystalline Massif, which is characterized by tectonic stability.

The main feature of the Ukrainian Crystalline Massif is the conditions of its bedding - in the western section, the crystalline rocks are bending on its surface, while the eastern section runs sharply downwards so, along the high right bank of the Dnieper River, these rocks lie at depths of 300 to $350 \mathrm{~m}$, while on the left bank, these rocks lie at depths of more than $600 \mathrm{~m}$. So, we have a transition from the Dnieper Highland to the Dnieper Lowland.

Therefore, the modern Dnieper riverbed flows along the largest tectonic fault in the country, which is currently in a stable state.

Geo-structurally, the studied area belongs to the Dnepr-Donetsk depression in the area of its joining to the Ukrainian Crystalline Massif in the west, where crystalline metamorphosed rocks are at a depth of more than $300 \mathrm{~m}$, overlapped by Paleozoic-Cenozoic deposits. The border between them is the Dnieper fault. The tectonic motion is characterized by slow differential vertical upward and downward movements of the Earth's crust. In modern conditions, this does not cause any special changes to the surface at ground level.

\subsection{Geomorphological zoning of the territory}

The geomorphological structure of Kyiv is difficult (fig. 2) [6]. The raised areas belong to the loess plateau, loess remnants, and water-glacial deposits, which are cut through a dense network of ravines and beams.

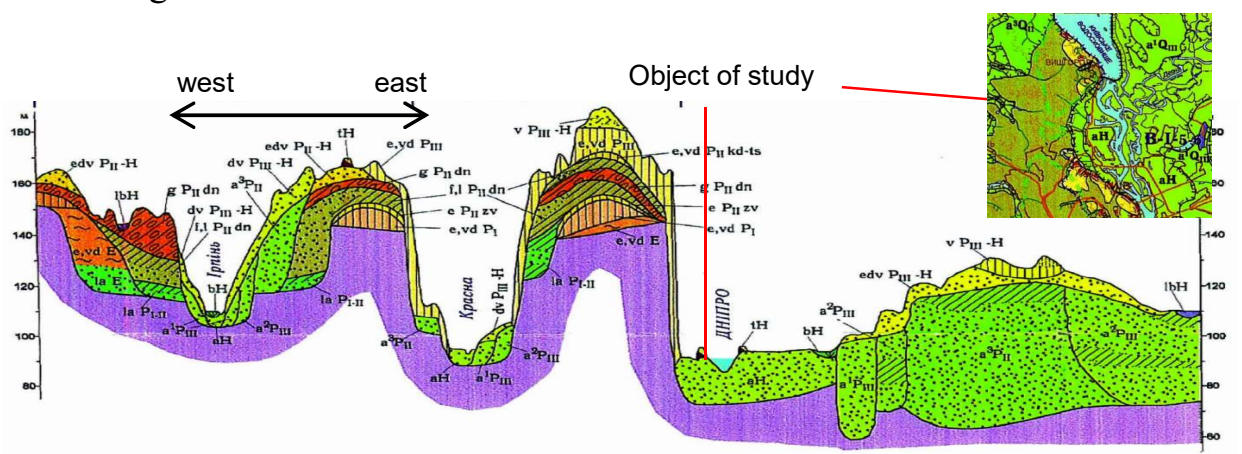

Fig. 2. Geomorphological zoning of the Kyiv territory [6]

The river Dnieper valley is characterized by asymmetry - the high right "indigenous" bank, which is eroded, and the redeployed low left bank.

From the literary sources, it is known that the river Dnieper's ancient watercourse formed more than 1.2 to 1.5 billion years ago, at a distance of 95 to $110 \mathrm{~km}$ to the east of Kyiv. As a result, the territory of the left bank is composed of alluvial terraces, which are "pressed" into each other. 
The thickness of the alluvial deposits increases to the east of Kyiv.

The northern territory of the city and the location of the study site belongs to the floodplain and is characterized by a considerable number of wetlands and large numbers of lakes and meadows.

In the geomorphological structure, the study site is located on the right bank of the river Dnieper, which in the '70s of the XX century, was raised to the levels of the Pleistocene non-floating terrace by hydraulic fill methods.

\subsection{Characteristics of floodplain deposits}

Floodplain deposits ebH (or lake-wetlands) are characterized by significant heterogeneity of layers (fig. 3). This is due, first and foremost, to the conditions of the formation of these soils, which is related to the work mode of the river. These are mainly weak and highly compressed soils with a reduced density, a small coefficient of filtration, and an ability to produce secondary consolidation under load.

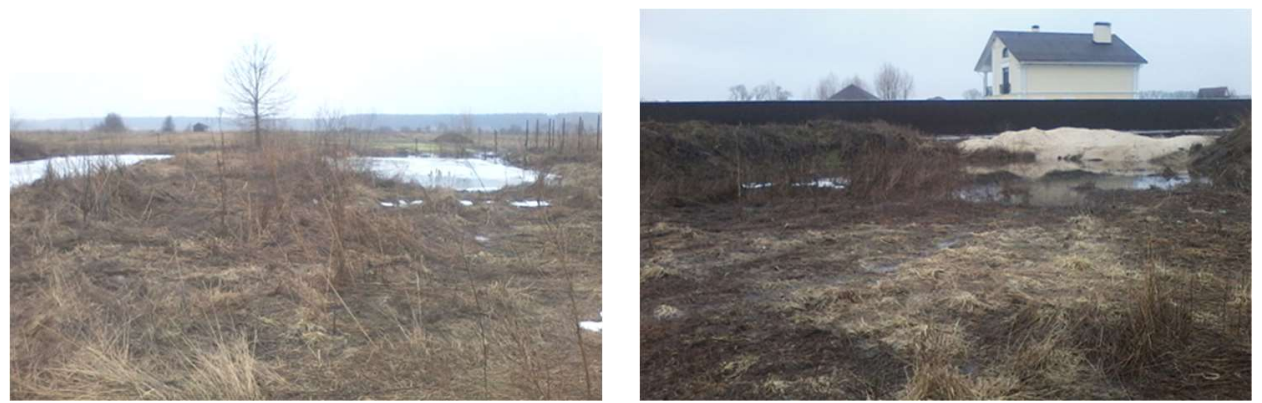

Fig 3. Floodplains of river Dnieper

Such soils in Ukraine are considered to be special.

The low strength value of the flood deposits is mainly a result of the humus content, the degree of its decomposition, and the conditions of these soils forming in time.

The presence of organic matter greatly reduces the coefficient of filtration of these soils, which show insufficient natural compaction taking into account their age. Weak soils lie on modern alluvial deposits (Holocene sands). But very often the sands themselves contain lenses and layers of peat, mud, or organic soils (fig. 4). The characteristics of such soils are shown in table 1 [5]. Another feature of the humus soils is their medium corrosive activity against concrete and high corrosive activity on metal. This should be taken into account when designing and building structures on such floodplain areas. 

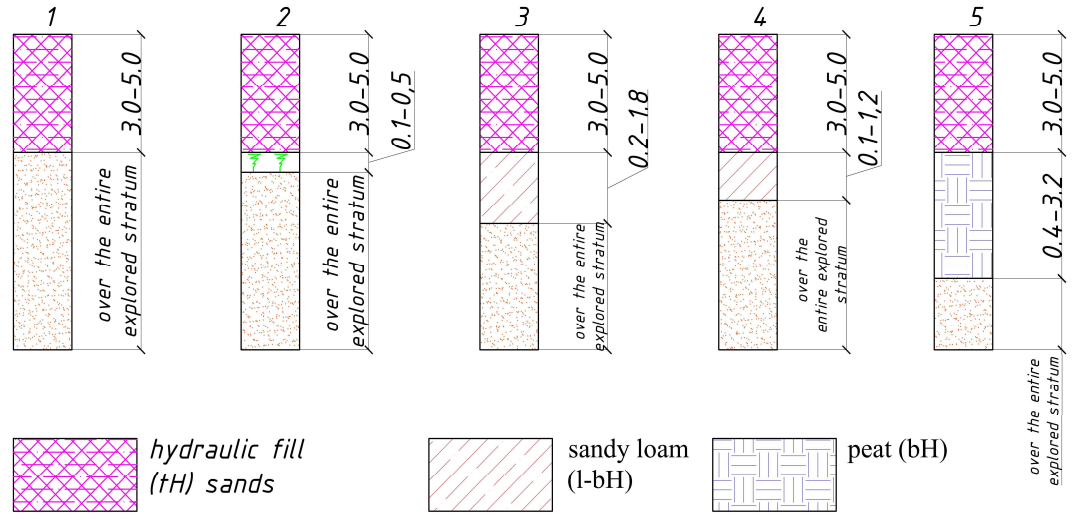

hydraulic fill $(t H)$ sands

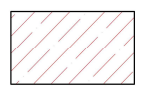

sandy loam $(1-b H)$

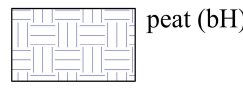

1 alluviul sands $(\mathrm{aH})$

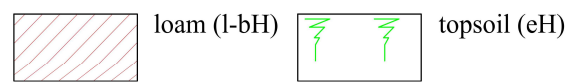

Fig 4. Floodplain deposits (possible variants) [5]

Table 1. The composition of floodplain alluvial soils [5]

\begin{tabular}{|c|c|c|c|}
\hline Soil & $\begin{array}{c}\text { Density, } \\
\rho, \mathrm{g} / \mathrm{cm}^{3}\end{array}$ & $\begin{array}{c}\text { Filtration coefficient } \\
\mathrm{k}_{\mathrm{f}}, \mathrm{cm} / \mathrm{c}\end{array}$ & $\begin{array}{c}\text { Secondary } \\
\text { consolidation rate } \\
\mathrm{m}_{\mathrm{V}}, \mathrm{cm}^{3} / \mathrm{H}\end{array}$ \\
\hline Peat & 1.09 & 0,00006 & $0.22 \ldots 0.67$ \\
\hline Peaty clay & 1.44 & $0.4 \cdot 10-5$ & 0.030 \\
\hline Sandy loam & 1.94 & 0.004 & 0.006 \\
\hline Dusty sand & 1.97 & 0.023 & 0.007 \\
\hline Fine sand & 1.96 & 0.25 & 0.002 \\
\hline
\end{tabular}

\subsection{Floodplain areas development}

From 1960 to 1962, it was decided to develop flood areas on the northern outskirts of Kyiv. To do this, it was necessary to solve several problems:

- protect the area from floodwater during flooding;

- remove adverse events such as humus soil consolidation;

- ensure the normal exploitation of buildings and underground networks (for example, they could be affected by the high level of groundwater and open surface waters).

Due to the need for these tasks, an engineering project of territory preparation was designed and realized with the use of the sandy soil hydraulic fill method on the Obolon residential area (fig. 5). 


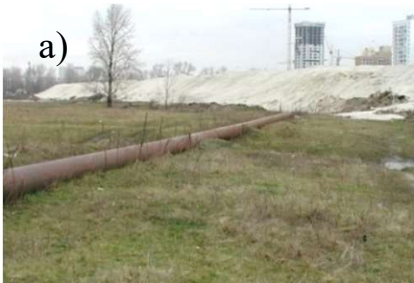

b)

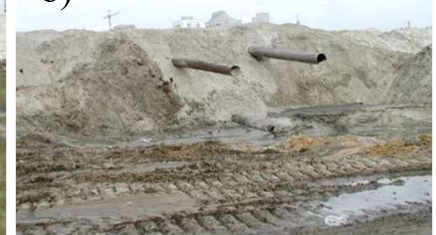

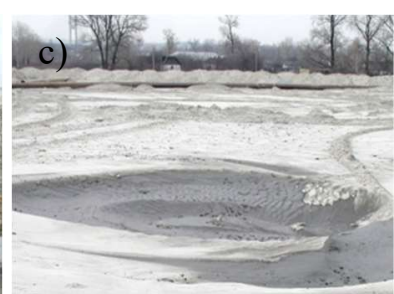

Fig 5. Regulation of territory with floodplain deposits

a) pipeline; b) sand dams; c) area after hydraulic fill

Hydraulic fill material was taken from the local alluvial sand of the river Dnieper bed facies. It was carried both directly from the main channel of the river, and the flowing tributary streams parallel to the Dnieper.

Preparatory work was carried out - temporary buildings and structures were taken down, engineering networks were transferred, trees and bushes were dug out. The territory was rotated into separate areas for the hydraulic filling that would follow. On the areas that were set for residential buildings and multi-story buildings, construction and household rubbish were removed to areas that were in reserve or allocated for industrial buildings. Then, mass peat removal was carried out (cutting weak layers from the ground surface to the groundwater level) with the next storage of cut material along the area's contour.

Thus, the investigation territory is located in the last zone, which was previously in reserve. Here, the accumulation of construction rubbish and humus cut off's took place.

\subsection{Hydraulic fill methods used for the Kyiv region}

Hydraulic filling was made within the allocated areas, forming the so-called "hydraulic fill maps" (fig. 6, 7) [5].

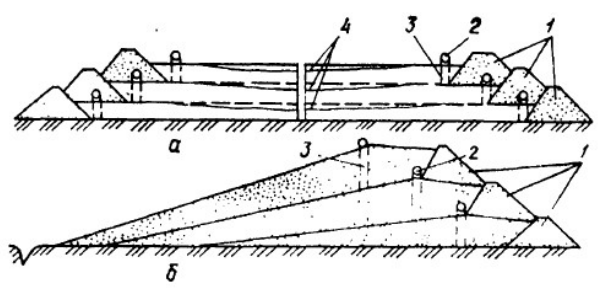

Fig 6. Hydraulic fill areas [5]: a) double-sided; b) and one-sided; 1 - dam, 2- pipeline, 3 - low supports, 4 - layer thickness 
Firstly, the bottom layer was formed, while the pulp line was kept permanently moving with the help of crawler machines. Further, the following layers were formed by the height. The total thickness of the hydraulic fill within the Obolon area is 3 to $7 \mathrm{~m}$.

After the hydraulic fill process, it was very important to have a technological break for consolidation of hydraulic fill soils and soils of the natural layering that lie below.
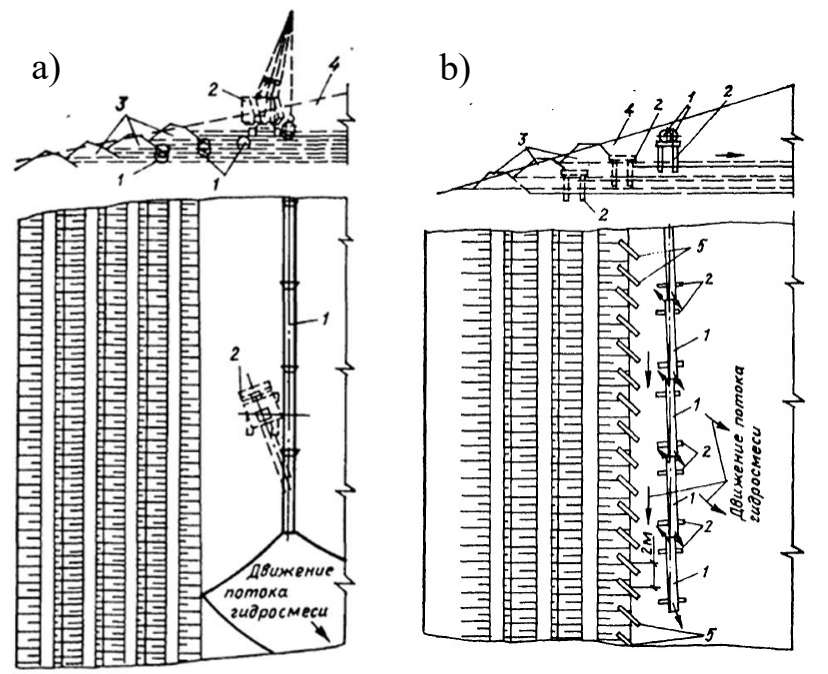

c)

Fig 7. Hydraulic fill areas [5]: a) non-trestle method: 1 - distribution pipeline, 2 - crane, 3- dams, 4 - project slope; b) low support casting method with distribution on both sides:

1 - pipeline links, 2 - low supports, 3 - dams, 4 - project slope, 5 - bumper plates;

c) mosaic method: 1 - drainage prism, 2- main pipeline, 3 - distribution pipeline,

4 - sump, 5 - discharge pipe, 6 - base

The time needed to produce a hydraulic fill on one working map was 1 to 3 months. To fix the process of self-compacting, geodesic signs were placed on the top of native deposits, and in the thickness of the hydraulic fill layers geodesic marks. The most active deformations occurred during the first three months and then fell away sharply.

It should be noted that during hydraulic fill the proportion of sand / water in the pulp was about 1: 100 to 1: 5000, meaning the volume of water during hydraulic fill was very large. Therefore, the process of soil compaction during hydraulic fill occurred in the following stages:

- at first there was compaction of the soils under the influence of a water column;

- following this, a filtration stream directed downwards (under the action of gravity) was installed, and hydrodynamic force also applied (also 
directed to the bottom). This "pulled" each sandy particle individually and produced additional compaction. The compaction from the hydrodynamic force was much higher than from the pressure of the water (column of water).

The greater the thickness of hydraulic fill soils we have, the more efficiently the lower layers were compacted [2]. To establish the terms of construction after hydraulic fill, observations [5] of hydraulic fill soil deformations were made (fig. 8). Studies have found that the largest deformation occurs in the first two months after the hydraulic fill. Measurement of the water level in the piezometers (fig. 9) [4] shows that the water is lower by 2 meters after a month and 3 meters after two months from the end of the hydraulic fill.

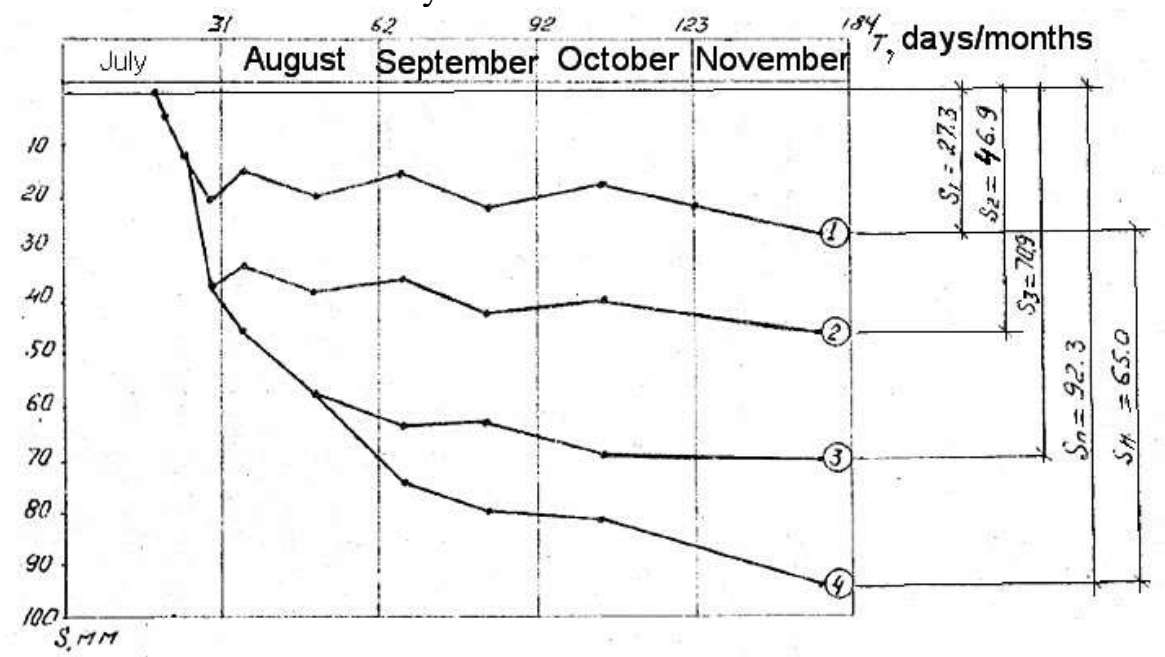

Fig 8. Geodesic signs settlement on the experimental site of the 5th Obolon micro district [5]: 1- signs settlement at contact with underlying alluvial soils; 2- signs settlement installed at a depth of $2.5 \mathrm{~m}$ from the design hydraulic fill profile; 3 - signs settlement installed at a depth of $2.0 \mathrm{~m}$ from the design hydraulic fill profile; 4- signs settlement installed at a depth of $0.5 \mathrm{~m}$ from the design hydraulic fill profile 


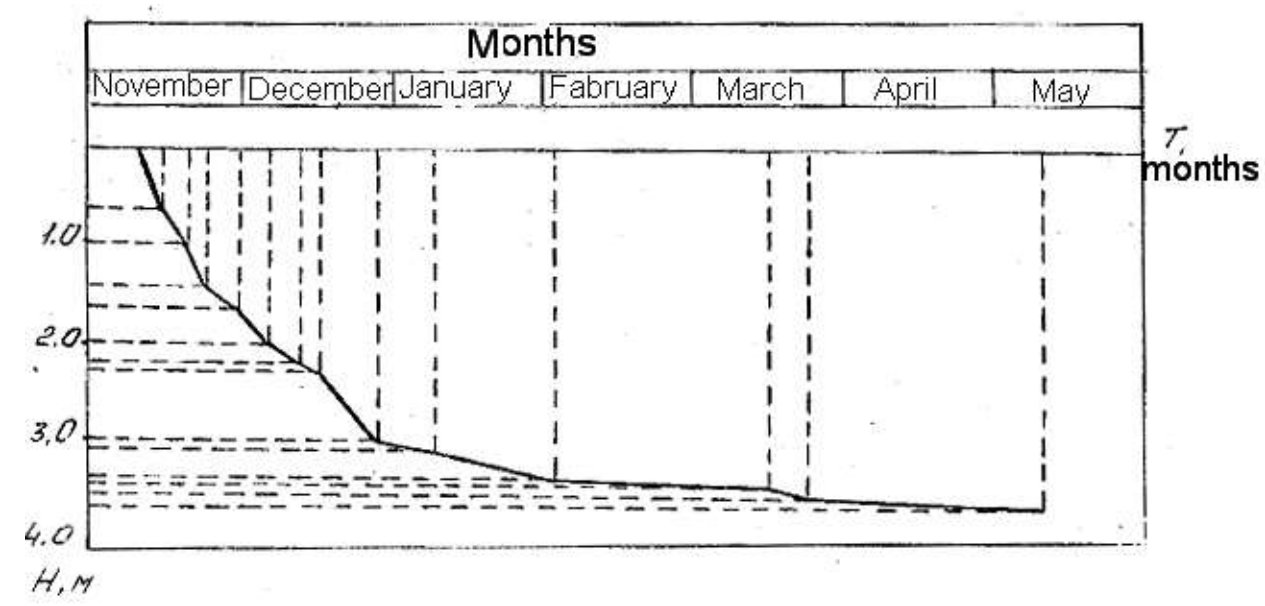

Fig 9. Filtration stream rate fall after hydraulic fill [4]

During the hydraulic filling work, there is a considerable flow of water (pulp). After it is poured onto the surface, the material is spread over the plane of the hydraulic fill map. The material is sorted by gravity with the largest particles settling directly near the place of pouring and the thinner particles moved to a higher distance (fig. 10) [4]. In the main thickness of the hydraulic fill, well-sorted homogeneous fine sand (medium and small) is dominant. This action greatly improves the quality of the soil for its further use as the ground base of foundations when compared with filled soils.

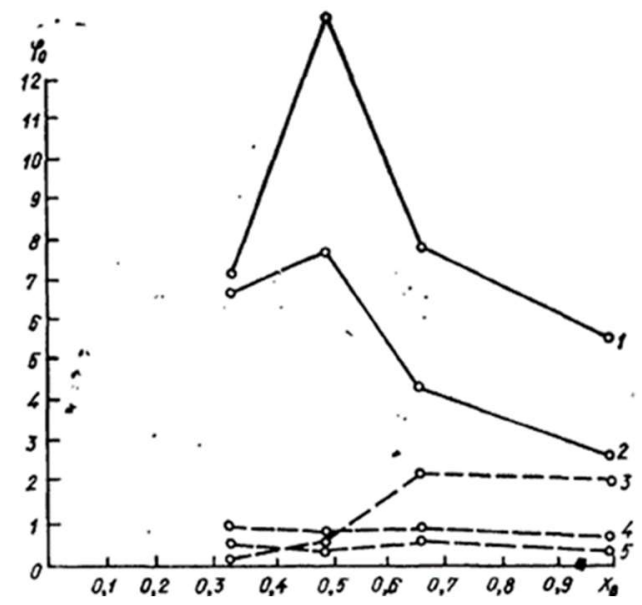

Fig 10. Fraction dispersion curves along the hydraulic fill slope of the Obolon micro district [4]: $1-5$ - fractions respectively $1.0 \mathrm{~mm}, 1.0 \ldots 0.5 \mathrm{~mm},<0.1 \mathrm{~mm}, 0.5 \ldots 0.25 \mathrm{~mm}$, $0.25 \ldots 0.1 \mathrm{~mm}$ 
Only in cases when the dredge thickness was not sufficient in the body of the hydraulic fill was it possible to find sand with a quantity of dust up to $20 \ldots .30 \%$ (dusty sands).

Analysis of the sand homogeneity by depth (table 2) shows that the composition of the sand is almost homogeneous, with only a slight increase in the number of fine particles with depth [5]. Table 4, at a depth of $4 \mathrm{~m}$, shows the location of the topsoil, which was not cut before the start of the hydraulic filling.

Table 2. Grade analysis of sands by depth [5]

\begin{tabular}{|c|c|c|c|c|c|c|}
\hline \multirow{2}{*}{$\begin{array}{c}\text { Depth } \\
\text { from } \\
\text { ground }\end{array}$} & \multirow{2}{*}{$\begin{array}{c}\text { Sample } \\
\text { number }\end{array}$} & \multicolumn{5}{|c|}{ Grading composition, \% by fractions, mm } \\
\cline { 3 - 7 } & & $>1.0$ & $1 \ldots 0.5$ & $0.5 \ldots 0.25$ & $0.25 \ldots 0.1$ & $<0.1$ \\
\hline 0.5 & 19 & 0.7 & 11.9 & 57.7 & 27.3 & 2.4 \\
\hline 1.0 & 12 & 0.9 & 8.2 & 67.7 & 20.4 & 2.7 \\
\hline 1.5 & 2 & 0.7 & 9.1 & 42.6 & 44.4 & 3.2 \\
\hline 2.0 & 13 & 0.9 & 10.4 & 51.6 & 33.8 & 3.3 \\
\hline 2.5 & 36 & 1.6 & 9.8 & 47.4 & 36.5 & 4.7 \\
\hline 3.0 & 17 & 1.0 & 11.6 & 49.7 & 33.0 & 4.7 \\
\hline 3.5 & 5 & 0.9 & 8.3 & 42.7 & 37.7 & 10.4 \\
\hline 4.0 & & \multicolumn{7}{|c|}{ topsoil } \\
\hline
\end{tabular}

\section{EXPERIMENTAL RESEARCH OF HYDRAULIC FILL SOILS}

\subsection{Archive experimental data analysis}

Taking into account the large scale of the hydraulic filling project within the Obolon district, and the small amount of actual materials for [analysis of] hydraulic fill soil behavior, within the "Obolon" suburbs, micro-districts were allocated, and additional geological research was carried out in each of them [3]. After confirmation of the geological stratigraphy (by drilling method), static soil tests were carried out with the help of round stamps with an area of $5000 \mathrm{~cm}^{2}$ and $10000 \mathrm{~cm}^{2}$. The stamps were installed both on the top surface of the hydraulic fill soils and at different depths beneath them. They were loaded with a static load which created a pressure of $0.5 \mathrm{MPa}$ at the base, with steps of 0.05 MPa. Stabilization of deformations at each load level did not exceed $0.1 \mathrm{~mm}$ during the last hour of observations. Then, a dependence of the settlement from the pressure under the stamp was built and, with its help, the secant stiffness modulus was determined [5]. 
Tests showed that from a depth of 1 to $1.5 \mathrm{~m}$, the sands have medium values of density, and from a depth of 2 to $2.5 \mathrm{~m}$, they are in a dense state (the deformation module $\mathrm{E}>30 \mathrm{MPa}$ ). This is confirmed by the plot of the void ratio change by depth (fig. 11) [5]. The average soil strength characteristics are shown in table 3 [5].

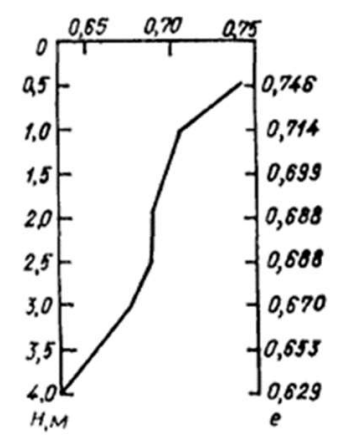

Fig 11. Distribution of void ratio value from depth for the construction of the «Obolon» district [5]

Table 3. Average values of hydraulic fill sandy soils characteristics [5]

\begin{tabular}{|c|c|c|c|}
\hline \multirow{2}{*}{ Soil parameters } & \multicolumn{3}{|c|}{$\begin{array}{c}\text { Values of soil parameters at the void ratio } \\
\text { (above the line are the values for medium- } \\
\text { grained sands, under-for fine sands) }\end{array}$} \\
\cline { 2 - 4 } & $0.51 \ldots 0.60$ & $0.61 \ldots 0.70$ & $0.70 \ldots 0.80$ \\
\hline Cohesion C, MPa & $\underline{0.002}$ & $\underline{0.001}$ & $\underline{0.000}$ \\
\hline Friction angle "fi", deg & $\underline{36}$ & $\underline{32}$ & $\underline{36}$ \\
\hline $\begin{array}{c}\text { Secant stiffness modulus, } \\
\mathrm{MPa}\end{array}$ & $\underline{\underline{40}}$ & $\underline{\underline{30}}$ & $\underline{\underline{30}}$ \\
\hline
\end{tabular}

The control boreholes exposed numerous cases where humus and peaty soils were present under a layer of hydraulic-filled soils. This is due to the quality of work that was done. Therefore, for each new construction project, additional geological investigations must be carried out.

\subsection{Investigation site 1}

For example, on one new construction site which was also used for a "Pile-test" project, additional engineering and geological investigations were carried out (fig. 12) [9], [10]. The "Pile-test" project took place in order to determine the bearing capacity of both a single pile and groups of piles as well as stress distribution in the ground base during pile work under vertical static load using various 
calculation methods, and their comparison with field test results on a given site, and subsequently to choose the most efficient of these.

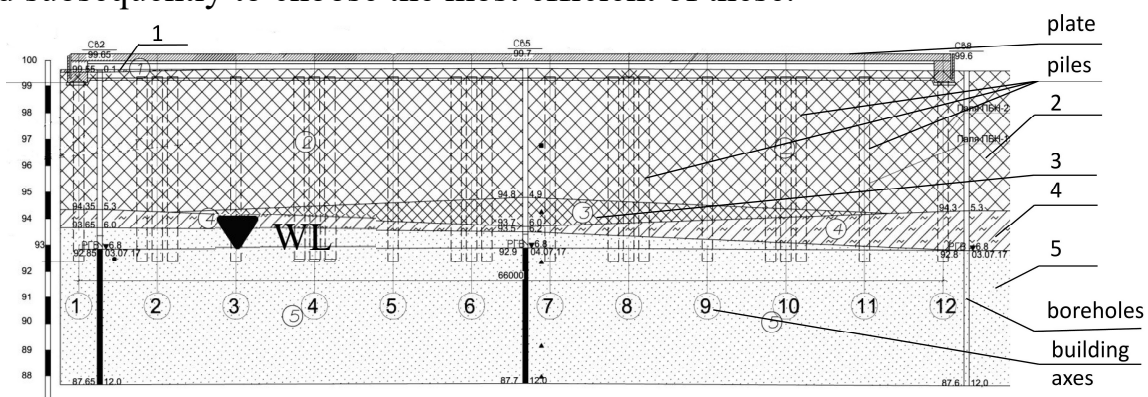

Fig 12. Geological conditions of "Pile-test" investigation site:

1 - asphalt; 2 -hydraulic filling layer: medium density, fine sand; 3 - hydraulic filling layer: dense fine sand; 4 - slightly peaty loam; 5 - medium density and dense fine sand
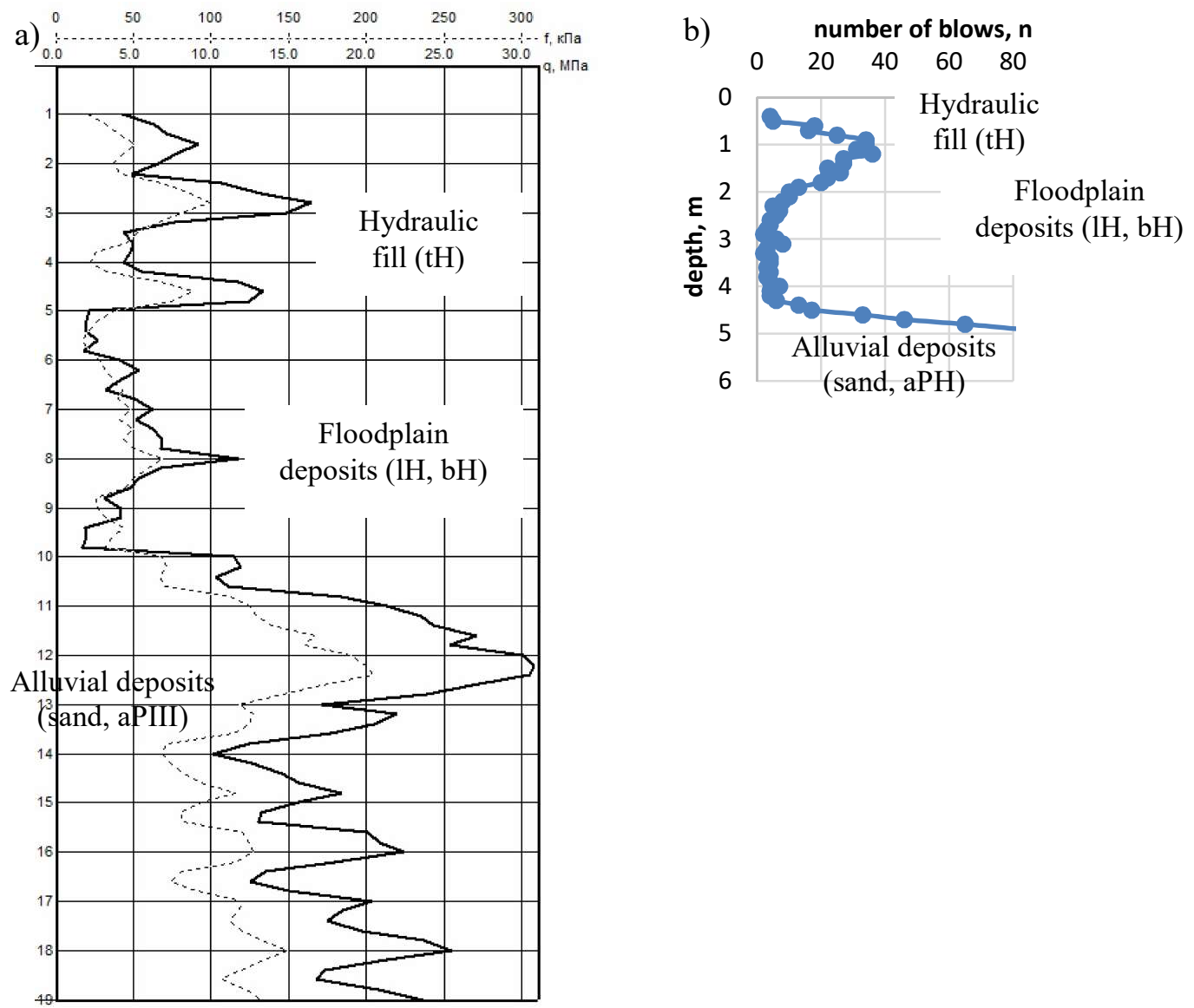

Fig 13. Field tests of "Pile-test" investigation site: a) CPT; b) DP test (DPL) 
We can, therefore, say that below groundwater level, weak soils like peat lie in certain parts of the river deposits, along with loam. Self-compacting of hydraulic soils and additional settlement as a result of incomplete consolidation of the underlying peaty soil layers can occur. In addition, soils that lie above and underneath the peaty loam can have low mechanic and deformation values. For that reason, a cone penetration test (CPT) (fig. 13, a) and dynamic penetration light test (DPL) (fig. 13, b) were carried out to confirm the quality of the hydraulic fill and underlying soils.

The results of the DPL tests also confirm that up to a depth of 1 to $1.5 \mathrm{~m}$, the thickness of the hydraulic filling is characterized by increased values of deformations $(\mathrm{E}=12 \ldots 15 \mathrm{MPa})$, and, with increasing depth, the quality of sand increases sharply $(\mathrm{E}=27 \ldots 30 \mathrm{MPa})$. The thickness of hydraulic fill sands (at depths of 6 to $7 \mathrm{~m}$ ) is characterized as absolutely reliable for construction purposes.

\subsection{Investigation site 2}

we will also provide our own results of geological research within the same floodplain area but at a distance of about $1.5 \mathrm{~km}$ to the south as additional confirmation of the general structure of hydraulic fill areas.

The geological structure of the second site has been determined to a depth of $20 \mathrm{~m}$ from ground level and is represented by a complex of modern Neo-Pleistocene sediments lying from top to bottom (fig. 14).

A) Holocene deposits:

- a man-made layer of hydraulic fill soils (tH) EGE-1 with a thickness of about $3.8 \mathrm{~m}$. When void ratio e is 0.69 , the cohesion $\mathrm{C}$ is $0.002 / 0.001 \mathrm{MPa}$; friction angle "fi" is $27 / 25 \mathrm{deg}$; secant stiffness modulus $\mathrm{E}$ is $17 / 16 \mathrm{MPa}$ (values for natural humidity are in the numerator, and for water saturation, in the denominator);

- alluvial deposits - Holocene (aH), represented by EGE-3 (quartz sand, fine, dense, and medium density, water saturated), has the following characteristics: $\mathrm{C}$ $=0.002 \mathrm{MPa} ; \mathrm{fi}=30 \mathrm{deg} ; \mathrm{E}=26 \mathrm{MPa}$; - silted sandy loam EGE-2a C $=0.005$ to $0.007 \mathrm{MPa}$; fi $=13$ to $15 \mathrm{deg} ; \mathrm{E}=6$ to $8 \mathrm{MPa}$, and fine soft sand with layers of silted sandy loam EGE-2; $\mathrm{C}=0.0005$ to $0.001 \mathrm{MPa}$; fi $=23$ to $25 \mathrm{deg}$; $\mathrm{E}=10$ to $12 \mathrm{MPa}$, which lie between EGE-1 and EGE-3. They were not removed before hydraulic filling. 


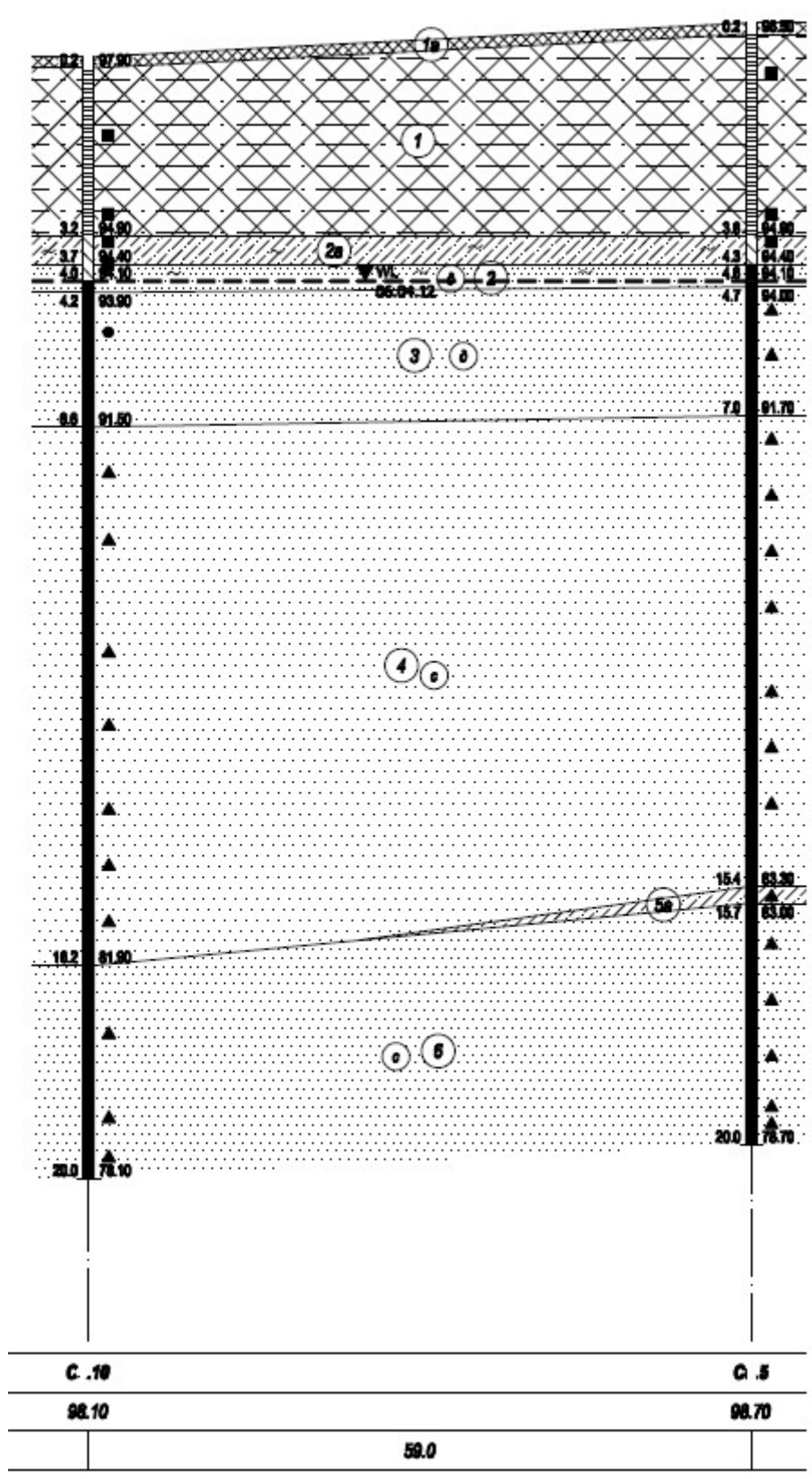

Fig 14. Geological conditions of the second investigation site:

$1 \mathrm{a}$ - asphalt, 1 - man-made layer of hydraulic fill soils, $2 \mathrm{a}$-silted sandy loam, 2 - fine soft sand with layers of silted sandy loam, 3 - medium density fine sand, 4 -medium density medium size sand 
B) Pleistocene deposits:

- Upper and Middle Pleistocene (aPIII, aPII) is represented by EGE-4 (quartz sand, fine and medium size, medium density, water saturated) and EGE-6 (quartz sand, medium size, dense, water saturated). These soils are reliable for building purposes, from detached houses with small pressure $(100 \mathrm{kPa})$ on the ground base, through to high-rise buildings with much higher pressure values (more than 300 $\mathrm{kPa}$ ), characteristics: $\mathrm{C}=0.003$ to $0.005 \mathrm{MPa}$; $\mathrm{fi}=32$ to $37 \mathrm{deg}$; $\mathrm{E}=38$ to $56 \mathrm{MPa}$. In general, the characteristics of investigation site 2 presented above match with values shown in table 3 of the previously considered investigation site.

The same features of geological structure and characteristics of soils were also noted in Kaminsky's work [11].

Geotechnical investigations which were carried out on the second investigation site, and which included cone penetration tests (CPT) (fig. 15, a) and dynamic penetration light tests (DPL) of soils (fig. 15, b), confirmed that the density of alluvial soils is dependent on the features of the hydraulic fill soils and the layer on which hydraulic filling was produced.

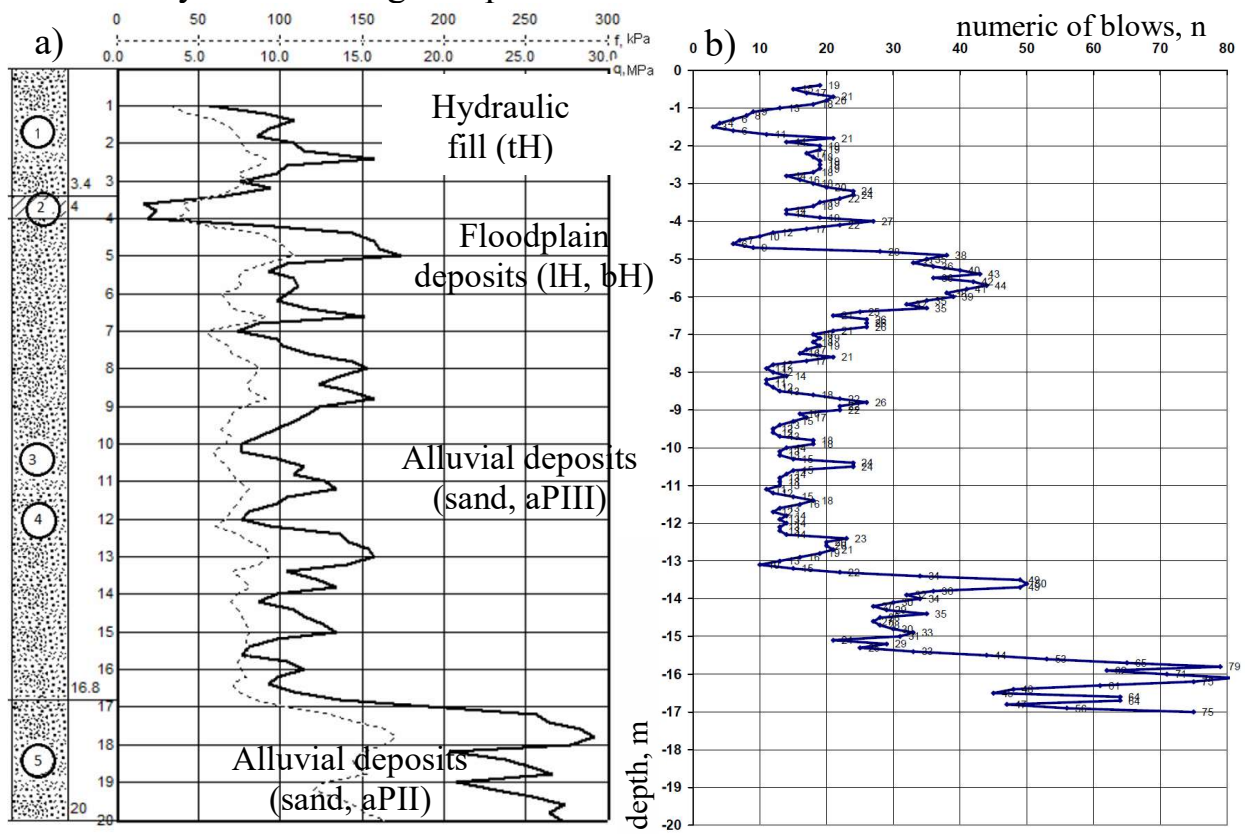

Fig 15. Field tests results on the second investigation site: a) CPT; b) DP test (DPL)

If the hydraulic filling occurs on soils with low mechanical characteristics (EGE2, EGE-2a) with silted sandy loam, then the middle section of the hydraulic fill soils is characterized by its softness (Fig.19.b): $\mathrm{qs}=2.5 \mathrm{MPa}, \mathrm{E}=7 \mathrm{MPa}, \mathrm{e}=0.8$. This is due to poor water outflow after hydraulic filling due to the reduced hydrodynamic force and, as a result, the hydraulic fill soils to a depth of 1 to 1.5 
$\mathrm{m}$ are characterized by increased values of deformations $(\mathrm{E}=17 / 16 \mathrm{MPa})$.

It was found that in the indigenous alluvial deposits below the water level, the particle size of sandy soil (diameter) increases with depth. For alluvial deposits (sand, aPIII), the average diameter is $0.7 \mathrm{~mm}$, and for alluvial deposits (sand, aPII), the average diameter is $2.3 \mathrm{~mm}$.

Dynamic penetration light tests (DPL) show that for medium density sands, the number of blows is reduced (14 in comparison with 50), at the same time, the cone penetration test (CPT) results show that qs is more than $20 \mathrm{MPa}$.

As a rule, in such soil conditions, when transferring significant load to the ground base (more than $300 \mathrm{kPa}$ or more than $2000 \mathrm{kN}$ on a column), we recommended using foundations that cut through the soils in which uneven deformations appear, and into deepening, more reliable soils.

For a more complete understanding of the processes occurring on the soils, analysis and observation of already-constructed building deformations were performed (fig. 16) [5]. As a result of undetected lenses of peat loam and clay during engineering-geological investigations, the building was designed with piles $4 \mathrm{~m}$ long and $30 \times 30 \mathrm{~cm}$ in the section underneath. Due to undetected peat lenses in the middle part of the building, it has undergone a long period of deformations (for 7 years) which have reached a value of $9.8 \mathrm{~cm}$ in the middle and $2.3 \mathrm{~cm}$ at its corners.

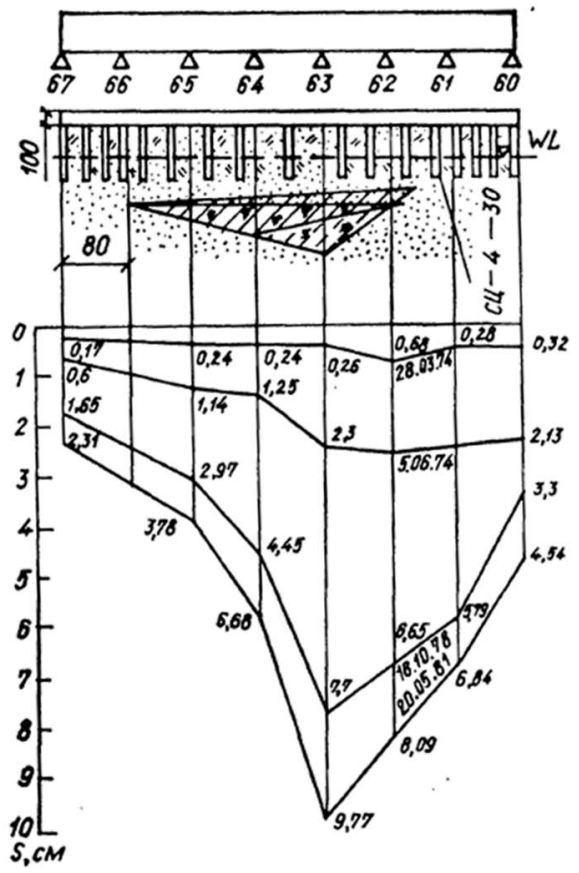

Fig 16. Settlement of houses in time 


\section{CONCLUSIONS}

1. It is established that in geo-structural terms, the investigation area belongs to the Dnieper-Donetsk depression, on a place at its junction with the Ukrainian Crystalline Massif.

2. Geomorphologically, the area corresponds to a plain built of horizontal strata, formed on a blurry surface of Paleogene-Cretaceous deposits which, in the 70 s, was raised to the levels of the Pleistocene by hydro-mechanization methods.

fluvial terrace above floodplain.

3. the area of hydrographic value investigation refers to the river Dnieper basin and is situated at a distance of $3.2 \mathrm{~km}$ from its channel.

4. The basic variants and features of hydraulic fill technology and the formation of the geological structure of hydraulic fill soil thickness are given.

5. It is established that the largest deformations of hydraulic fill soils are completed in two months and the groundwater level becomes lower by three meters at the same time after hydraulic filling.

6 . The main strength values of hydraulic fill soils are given.

7. It is established that the hydraulic fill area in the upper part (up to $1.5 \mathrm{~m}$ ) is characterized by increased deformability, and the lower part, from a depth of $8 \mathrm{~m}$ is reliable for construction purposes. The middle part, represented by hydraulic fill soils, is characterized by high rates of its physical and mechanical soil parameters.

8. Separation of the natural alluvium thickness by age and physical and mechanical characteristics has been done (alluvial sand deposits aPIII and aPII), which should be taken into account when determining the quality of hydraulic fill soils, and choosing a rational foundation type.

9. The deformation analysis of buildings and structures shows the purpose of careful geological investigations to identify unacceptable layers of humified and peaty weak soils that may lie on indigenous alluvial deposits and the realization of static or dynamic probing tests on a reduced pitch grid.

\section{REFERENCES}

1. Dalmatov, B 1974. The experience of building and designing buildings on soft and alluvial soils. Materials of the 1st Republic conference about floodplain construction on the alluvial territories of Belarusian Polesie, Homel, 82-89.

2. Konovalov, P and Nikiforova, N 1980. Investigation of the deformability of heterogeneous alluvial structures. Prospects and economics of construction in alluvial territories, 86-89. 
3. Konovalov, P 1985. Recommendations for engineering and geological surveys and designing the foundations of buildings and structures in alluvial areas. Moskow: NIIOSP.

4. Slyusarenko, S 1984. Construction properties of alluvial sandy soils of the territory of the Ukrainian SSR. Kyiv: NIISP.

5. Slyusarenko, S and Stepanenko, G 1990. Design and installation of foundations on alluvial sandy soils. Kyiv. Budivelnyk.

6. http://geoinf.kiev.ua/wp/w/Viewer.php? $\mathrm{pr}=1 \& u m p=m 36-13 \& \mathrm{fmp}=\mathrm{kv} \_\mathrm{m} 36-$ 13_1.pdf

7. https://uk.wikipedia.org/wiki/Геологічна_карта

8. https://ru.wikipedia.org/wiki/Рельеф_Украины

9. Szajna, W, Sakharov, V, Boyko, I 2019. Pile tests - 2019. Geotechnical characteristics of the site. Proceedings of Third International Conference "Challenges in Geotechnical Engineering", Zielona Góra, Poland, September, 10-13, 43-48.

10. Sakharov, V, Szajna, W, Boyko, I 2019. In situ Pile tests - 2019 project. Methodology and results. Proceedings of Third International Conference "Challenges in Geotechnical Engineering", Zielona Góra, Poland, September, 10-13, 49-50.

11. Kaminsky, VI 2009. Features of the design and formation of alluvial territory for the construction of the marine passenger terminal in St. Petersburg. Mining Information and Analytical Bulletin (Scientific and Technical Journal), 1 (12), 444-451.

Editor received the manuscript: 12.12.2019 